\title{
A New Therapeutic Strategy for Streptococcal Toxic Shock Syndrome: A Key Target for Cytokines
}

\author{
Takayuki KawaguchI, Naoya IgAKI, Sinichi KinoshitA, Tomokazu MatsudA, Aritoshi KIDA, \\ Rintarou MoriguCHI, Makoto SAKAI, Fumihiko TAMADA, Munetada OIMOMI and Takeo Goto
}

\begin{abstract}
We searched for innovative treatments specifically targeted to the cytokines of three critically ill patients with streptococcal toxic shock syndrome (STSS). Direct hemoperfusion with polymyxin B-immobilized fiber improved the hemodynamics in all three patients who had developed shock at presentation. Continuous hemodiafiltration coupled with plasma exchange for simultaneous removal of several mediators of the inflammatory cascade improved outcome in case 2 and lessened the aggressive clinical course and prolonged survival in case 3 . The application of these technologies appears to open new and interesting therapeutic options and may lead to improved survival in STSS.
\end{abstract}

(Internal Medicine 42: 211-218, 2003)

Key words: continuous hemodiafiltration, direct hemoperfusion, polymyxin B-immobilized fiber, plasma exchange, inflammatory cascade

\section{Introduction}

Group A streptococci (GAS) are responsible for a wide spectrum of clinical illnesses, ranging from milder and more easily treatable infections such as pharyngitis, impetigo, and pyoderma to severe invasive disease, referred to as streptococcal toxic shock syndrome (STSS). The emergence of severe GAS infection since the 1980s has now been reported from most parts of the world (1-10).

STSS, an acute, progressive, and often fatal illness appears to be related to an overall change in the virulence of GAS and the reappearance of highly mucoid exotoxinproducing strains. Strains of GAS isolated from patients with STSS have been predominantly of M types 1 and 3, which produce either pyrogenic exotoxin A or B or both (1, 3-10). These streptococcal pyrogenic exotoxins (Spes) have been the subject of much attention because of their biological activity (11-14). They act as superantigens and induce the proliferation of $\mathrm{T}$ lymphocytes in vitro and the synthesis and release of several cytokines in vivo, including tumor necrosis factor- $\alpha$ (TNF $\alpha$ ), interleukin-1 $\beta$ (IL-1 $\beta$ ), and interleukin-6 (IL-6). The production of these exotoxins is associated with a marked febrile response, alteration of membrane permeability, and enhancement of host susceptibility to the lethal shock of endotoxin.

The pathogenic mechanisms of shock, multiple-organ failure, and tissue destruction in STSS are not fully understood, and there is about $30-50 \%$ mortality in patients with STSS despite several possibly feasible treatments consisting of surgical debridement, intravenous fluids, appropriate antibiotics, and intravenous immunoglobulin. Here, we report 3 cases of STSS and suggest a new therapeutic strategy for STSS emphasizing a key target for the cytokines.

\section{Case Reports}

\section{Case 1}

A 77-year-old woman undergoing hemodialysis (HD) for 10 years was referred with intractable lumbago and severe pain in the left thigh on June 28, 2000. The underlying disease of chronic renal failure was unknown. She had a past history of impetigo 4 years earlier. Initial examination was remarkable with a temperature of $36.0^{\circ} \mathrm{C}$, a pulse rate of 108 beats per minute, systolic blood pressure at $<60 \mathrm{mmHg}$, a respiratory rate of 28 beats per minute and her mental status was drowsy. Shock was apparent. Her left thigh was erythematous and swollen. Bacterial blood cultures were positive for Streptococcus pyogenes and thus immediate intravenous antibiotic therapy (imipenem/cilastatin; IPM/CS at a daily dose of $2 \mathrm{~g}$ and sultamicillin; ABPC/SBT at a daily dose of $12 \mathrm{~g}$ ) and intravenous immunoglobulin (IVIG) at a

From the Department of Internal Medicine, Takasago Municipal Hospital, Takasago

Received for publication July 31, 2002; Accepted for publication November 15, 2002

Reprint requests should be addressed to Dr. Naoya Igaki, the Department of Internal Medicine, Takasago Municipal Hospital, 33-1 Kamimachi, Arai-cho, Takasago 676-8585 
Table 1. Laboratory Data at Admission in Cases 1, 2 and 3

\begin{tabular}{|c|c|c|c|c|c|}
\hline \multicolumn{2}{|c|}{ Case 1} & \multicolumn{2}{|c|}{ Case 2} & \multicolumn{2}{|c|}{ Case 3} \\
\hline WBC & $18,020 / \mathrm{mm}^{3}$ & WBC & $9,020 / \mathrm{mm}^{3}$ & WBC & $15,680 / \mathrm{mm}^{3}$ \\
\hline $\mathrm{RBC}$ & $299 \times 10^{4} / \mathrm{mm}^{3}$ & $\mathrm{RBC}$ & $392 \times 10^{4} / \mathrm{mm}^{3}$ & $\mathrm{RBC}$ & $491 \times 10^{4} / \mathrm{mm}^{3}$ \\
\hline $\mathrm{Hb}$ & $9.0 \mathrm{~g} / \mathrm{dl}$ & $\mathrm{Hb}$ & $13.0 \mathrm{~g} / \mathrm{dl}$ & $\mathrm{Hb}$ & $16.3 \mathrm{~g} / \mathrm{dl}$ \\
\hline Plt & $7.3 \times 10^{4} / \mathrm{mm}^{3}$ & Plt & $13.1 \times 10^{4} / \mathrm{mm}^{3}$ & Plt & $14.5 \times 10^{4} / \mathrm{mm}^{3}$ \\
\hline CRP & $13.2 \mathrm{mg} / \mathrm{dl}$ & CRP & $16.2 \mathrm{mg} / \mathrm{dl}$ & CRP & $35.1 \mathrm{mg} / \mathrm{dl}$ \\
\hline $\mathrm{AST}$ & $31 \mathrm{IU} / l$ & AST & $37 \mathrm{IU} / l$ & AST & $274 \mathrm{IU} / l$ \\
\hline ALT & $20 \mathrm{IU} / l$ & $\mathrm{ALT}$ & $28 \mathrm{IU} / l$ & $\mathrm{ALT}$ & $119 \mathrm{IU} / l$ \\
\hline LDH & $244 \mathrm{IU} / l$ & $\mathrm{LDH}$ & $269 \mathrm{IU} / l$ & $\mathrm{LDH}$ & $115 \mathrm{IU} / l$ \\
\hline CPK & $221 \mathrm{IU} / l$ & CPK & $274 \mathrm{IU} / l$ & CPK & $12,523 \mathrm{IU} / \mathrm{l}$ \\
\hline $\mathrm{TP}$ & $4.3 \mathrm{~g} / \mathrm{dl}$ & $\mathrm{TP}$ & $4.3 \mathrm{~g} / \mathrm{dl}$ & $\mathrm{TP}$ & $5.6 \mathrm{~g} / \mathrm{dl}$ \\
\hline Alb & $2.6 \mathrm{~g} / \mathrm{dl}$ & Alb & $2.7 \mathrm{~g} / \mathrm{dl}$ & Alb & $2.8 \mathrm{~g} / \mathrm{dl}$ \\
\hline $\mathrm{Cr}$ & $6.3 \mathrm{mg} / \mathrm{dl}$ & $\mathrm{Cr}$ & $1.0 \mathrm{mg} / \mathrm{dl}$ & $\mathrm{Cr}$ & $5.3 \mathrm{mg} / \mathrm{dl}$ \\
\hline BUN & $55 \mathrm{mg} / \mathrm{dl}$ & BUN & $20 \mathrm{mg} / \mathrm{dl}$ & BUN & $83 \mathrm{mg} / \mathrm{dl}$ \\
\hline $\mathrm{Na}$ & $135 \mathrm{mEq} / \mathrm{l}$ & $\mathrm{Na}$ & $131 \mathrm{mEq} / \mathrm{l}$ & $\mathrm{Na}$ & $142 \mathrm{mEq} / \mathrm{l}$ \\
\hline $\mathrm{K}$ & $3.4 \mathrm{mEq} / \mathrm{l}$ & $\mathrm{K}$ & $3.5 \mathrm{mEq} / \mathrm{l}$ & $\mathrm{K}$ & $4.2 \mathrm{mEq} / \mathrm{l}$ \\
\hline $\mathrm{Cl}$ & $98 \mathrm{mEq} / \mathrm{l}$ & $\mathrm{Cl}$ & $103 \mathrm{mEq} / \mathrm{l}$ & $\mathrm{Cl}$ & $108 \mathrm{mEq} / \mathrm{l}$ \\
\hline$\beta$-D glucan & $225.7 \mathrm{pg} / \mathrm{ml}$ & $\beta$-D glucan & $2.2 \mathrm{pg} / \mathrm{ml}$ & $\beta$-D glucan & $2.38 \mathrm{pg} / \mathrm{ml}$ \\
\hline Endotoxin & $<1.81 \mathrm{pg} / \mathrm{dl}$ & Endotoxin & $5.85 \mathrm{pg} / \mathrm{dl}$ & Endotoxin & $5.41 \mathrm{pg} / \mathrm{dl}$ \\
\hline Blood gas & (room air) & Blood gas & (room air) & Blood gas & (room air) \\
\hline $\mathrm{pH}$ & 7.268 & $\mathrm{pH}$ & 7.557 & $\mathrm{pH}$ & 7.346 \\
\hline $\mathrm{pCO}_{2}$ & 31.2 Torr & $\mathrm{pCO}_{2}$ & 17.0 Torr & $\mathrm{pCO}_{2}$ & 21.7 Torr \\
\hline $\mathrm{pO}_{2}$ & 68.5 Torr & $\mathrm{pO}_{2}$ & 113.2 Torr & $\mathrm{pO}_{2}$ & 68.9 Torr \\
\hline $\mathrm{HCO}_{3}$ & $13.8 \mathrm{mmol} / \mathrm{l}$ & $\mathrm{HCO}_{3}$ & $15.2 \mathrm{mmol} / \mathrm{l}$ & $\mathrm{HCO}_{3}$ & $11.6 \mathrm{mmol} / l$ \\
\hline
\end{tabular}

daily dose of $5 \mathrm{~g}$ were initiated. Laboratory data at admission are presented in Table 1 . The level of TNF $\alpha$ was markedly elevated (Fig. 1). Despite the initial appropriate therapy with cathecolamines, hemodynamic instability and respiratory failure ensued. Mechanical ventilation was necessary due to the severity of acute respiratory distress syndrome (ARDS). Direct hemoperfusion (DHP) with polymyxin B-immobilized fiber (PMX) (Toraymixin, Toray Medical Inc., Tokyo, Japan) was performed for 2 hours in order to maintain the hemodynamics although endotoxin was not detected. Blood in the extracorporeal circuit was anticoagulated with nafamostat mesilate (Futhan, Torii, Tokyo, Japan). Blood flow (Qb) was controlled at $60 \mathrm{ml} / \mathrm{min}$ by a roller pump. After DHP with PMX followed by improvement of the hemodynamics, intermittent hemodiafiltration (IHDF) was started for 4 hours. Conditions for IHDF were adjusted as follows: $\mathrm{Qb} ; 100 \mathrm{ml} / \mathrm{min}$, dialysate flow (Qd), $500 \mathrm{ml} / \mathrm{min}$; replacement fluid; Sublood-B (Shimizu Inc., Kyoto, Japan) containing sodium, $140.0 \mathrm{mEq} / \mathrm{l}$; potassium, $2.0 \mathrm{mEq} / l$; chloride, $111.0 \mathrm{mEq} / l$; calcium, $3.5 \mathrm{mEq} / l$; magnesium, $1.0 \mathrm{mEq} /$ $l$; bicarbonate, $35.0 \mathrm{mEq} / l$; and glucose, $100.0 \mathrm{mg} / \mathrm{dl}$; dialyzer, PS-1.3 (polysulfone membrane with $1.3 \mathrm{~m}^{2}$ surface area, Toray Medical Inc.) and an individualized bedside console, model DBG-01 (Nikkiso Co., Tokyo, Japan). Despite maximal supportive therapies, she developed hepatic failure and died 27 hours after admission. At autopsy, extensive muscular necrosis and necrotizing fasciitis was evident in the buttock and thigh.

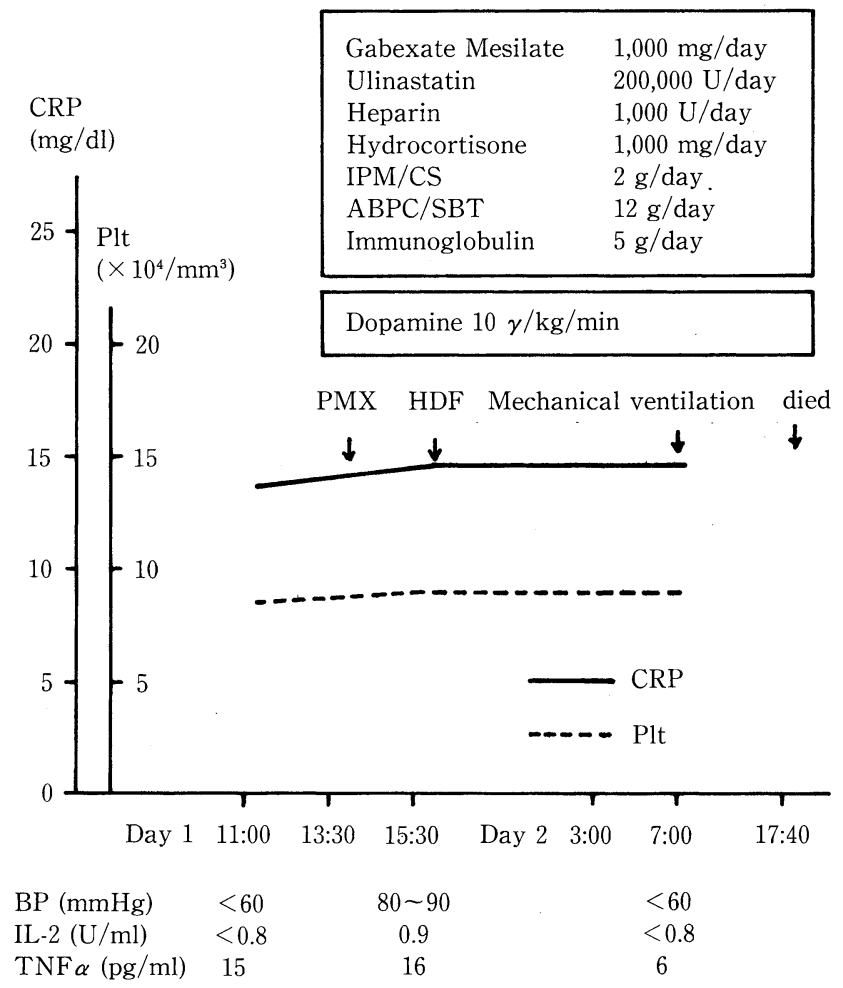

Figure 1. Clinical course of case 1. TNF $\alpha$ remained elevated despite DHP with PMX and IHDF which might be associated with aggressive clinical course. BP: blood pressure, Plt: platelet, PMX: polymyxin B-immobilized fiber, HDF: hemodiafiltration. 


\section{Case 2}

A 35-year-old woman was referred with severe pain in left thigh and buttock and high grade fever mimicking pelvic inflammatory disease on June 26, 2001. She had a past history of anorexia nervosa 4 years earlier. Initial examination was remarkable with a temperature of $36.5^{\circ} \mathrm{C}$, a pulse rate of 122 beats per minute, blood pressure at $72 / 50 \mathrm{mmHg}$, a respiratory rate of 20 beats per minute, and her mental status was drowsy. Shock was apparent. Her left thigh was erythematous and swollen (Fig. 2A). A generalized erythematous macular rash subsequently developed. Magnetic resonance image (MRI) revealed an inflammatory lesion in her left thigh (Fig. 3). Extensive debridement of her left thigh was performed twice (Fig. 2B); necrosis extended to the fascia, but not to the muscle with culture revealing Streptococcus pyogenes and Psedomonas aeruginosa. Bacterial blood cultures were only positive for Streptococcus pyogenes and so immediate intravenous antibiotic therapy (meropenem; MEMP at a daily dose of $2 \mathrm{~g}, \mathrm{ABPC} / \mathrm{SBT}$ at a daily dose of $12 \mathrm{~g}$, and clindamycin at a daily dose of 1,200 $\mathrm{mg}$ ) and IVIG at a daily dose of $5 \mathrm{~g}$ were initiated. Laboratory data at admission are presented in Table 1 . The serum creatinine kinase (CPK) level was normal, and surgical exploration confirmed that the muscle was not infected. The levels of IL-6 (Fig. 4) and endotoxin were remarkably elevated which suggested co-infection with gram-negative bacteria. Despite the initial appropriate therapy, anuria and acute renal failure ensued. To perform DHP with PMX, venovenous vascular access was achieved with a flexible doublelumen catheter via the right femoral vein. Two hours DHP was performed on the first day and the next day. Plasma exchange (PE) was also performed twice in which conditions were adjusted as follows: Qb, $50 \mathrm{ml} / \mathrm{min}$; replacement fluid, $3 l$ of fresh frozen plasma (FFP); dialyzer, Plasmaflow (Asahi Medical Inc.); and an individualized bedside console, Plasauto 2500 (Asahi Medical Inc., Tokyo, Japan). Continuous HDF (CHDF) was started on the second day of hospitalization in which conditions were adjusted as follows: $\mathrm{Qb}$, $100 \mathrm{ml} / \mathrm{min}$; Qd, $300 \mathrm{ml} / \mathrm{min}$; replacement fluid, Sublood-B; dialyzer, APF-06S (polyacrylonitrile, Asahi Medical Inc.) and an individualized bedside console, model ACH-10 (Asahi Medical Inc.). Following these therapies, hemodynamic, respiratory, and renal function parameters improved with increments of urinary output. After finishing the
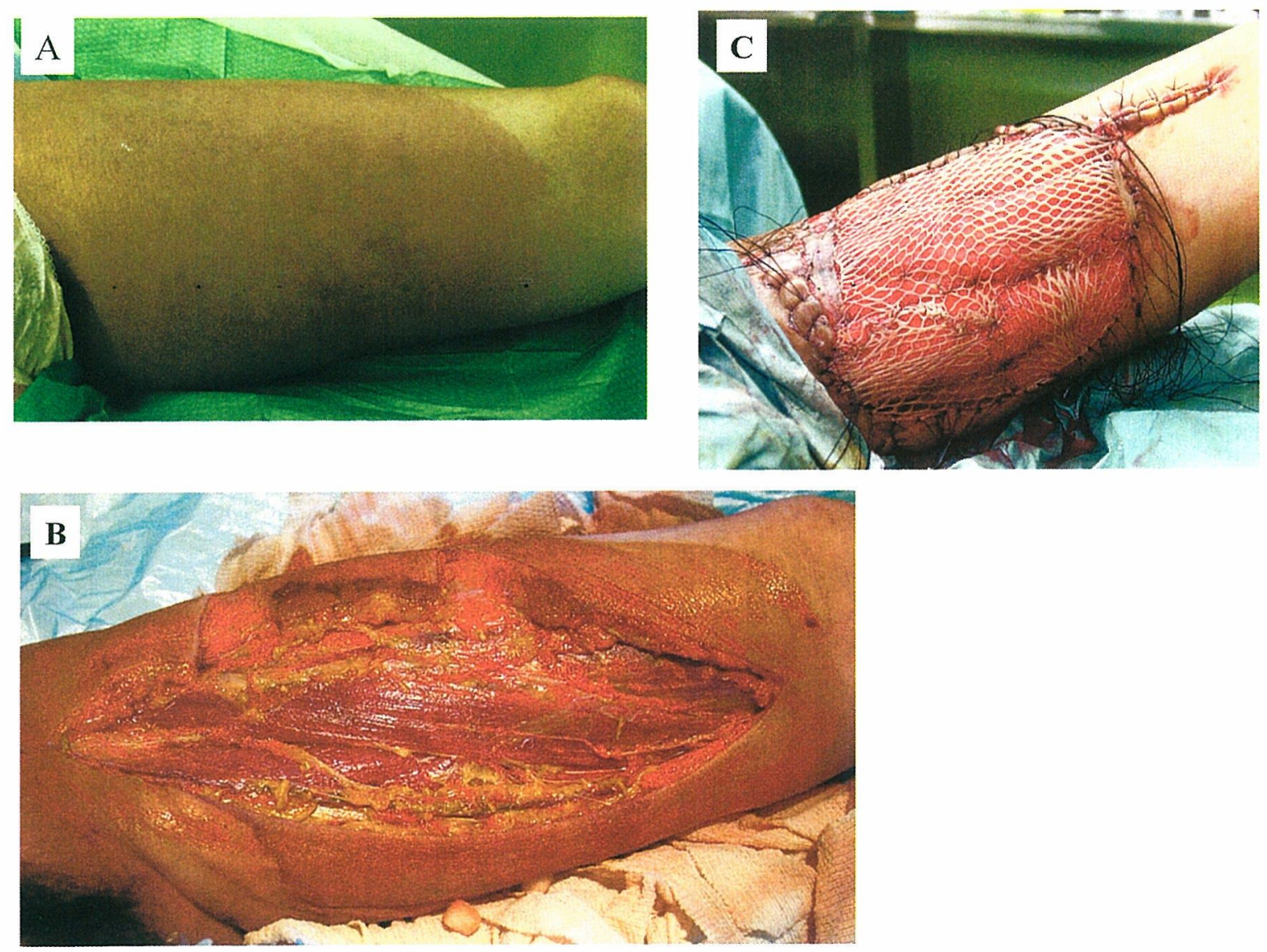

Figure 2. Photographs of case 2 show (A) erythematous and swollen thigh, (B) extensive debridement, and (C) autografted skin. 

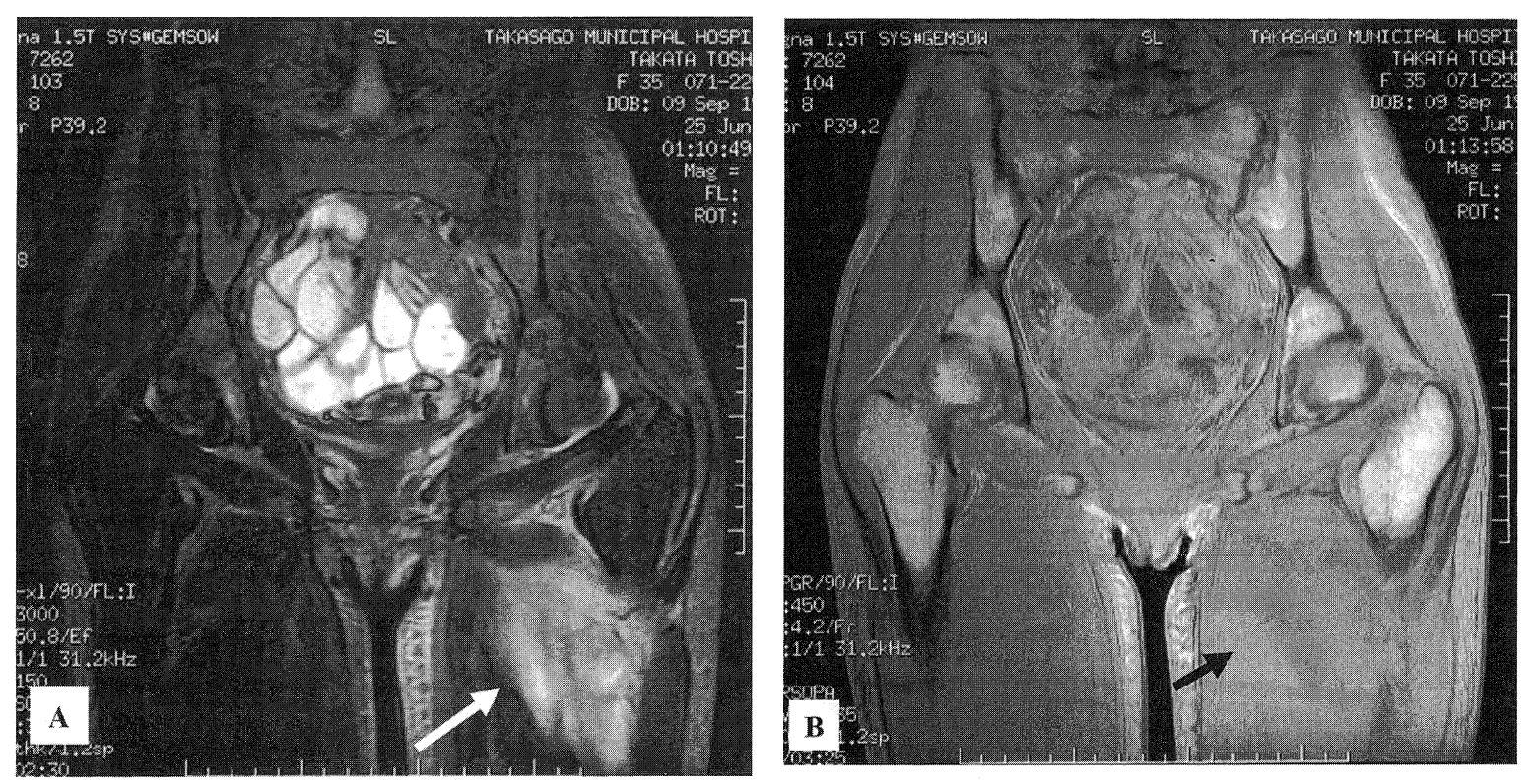

Figure 3. Magnetic resonance image (MRI) of case 2. (A) T1-weighted MRI showing high signal intensities (arrow), and (B) T2-weighted MRI showing low signal intensities (arrow) in the left thigh.

course of antibiotics, the patient remained afebrile with good wound healing and integrity by skin autografts (Fig. 2C).

\section{Case 3}

A previously healthy 63-year-old man was referred with shock and high grade fever, preceded by the local soft tissue trauma in his right thigh after a bicycle accident two days previously on August 16, 2001. Initial examination was remarkable with a temperature of $37.3^{\circ} \mathrm{C}$, a pulse rate of 143 beats per minute, blood pressure at $80 / 40 \mathrm{mmHg}$, a respiratory rate of 24 beats per minute, and his mental status was drowsy. Shock was apparent and mechanical ventilation was necessary at admission. His right thigh was erythematous and necrotic with vesicles and bullae (Fig. 5A, B). A generalized erythematous macular rash subsequently developed. Extensive debridement of his left thigh was performed (Fig. 5C); necrosis extended to the fascia and muscle with culture revealing Streptococcus pyogenes. Bacterial blood cultures were positive for Streptococcus pyogenes. He fulfilled all the proposed case definition criteria for the diagnosis of definitive STSS (2). Based on the treatment of case 2, immediate intravenous antibiotic therapy ( $2 \mathrm{~g}$ of MEMP, $12 \mathrm{~g}$ of $\mathrm{ABPC} / \mathrm{SBT}$, and 2,400 $\mathrm{mg}$ of clindamycin), IVIG at a daily dose of $5 \mathrm{~g}$, DHP with PMX, PE, and CHDF were initiated. Laboratory data at admission are presented in Table 1. The levels of CPK and IL-6 were markedly elevated (Fig. 6). Following these therapies, hemodynamic, respiratory, and renal function parameters improved with increments of urinary output. However, the patient remained febrile with superinfections and was malnourished with continuous protein loss from a wide area of wounds (Fig. 5D). Despite maximal supportive therapies, he died on the 24th day of hospitalization.

\section{Discussion}

Recent studies show an increasing incidence of grampositive sources of sepsis (15), and it is possible that these cases may predominate in the coming years. It appears that gram-positive organisms may also be more virulent in aggravating the disease, as can be evidenced by the emergence of STSS (1-10). This may result from the ability of grampositive organisms to produce more inflammation-causing cell wall constituents such as peptidoglycan and lipoteichoic acid, as well as unbound exotoxins. A single component of gram-negative organism (endotoxin) is believed to be involved in inciting sepsis (16). Endotoxin is relatively easy to purify and inject, and, because it is a single substance, the mechanisms by which gram-negative organisms cause sepsis can be mapped fairly simply. In contrast, a gram-positive organism contains a number of different substances that can initiate sepsis.

The approaches to therapy include surgical debridement, appropriate antibiotics (17) and intravenous immunoglobulin (18-20), and the resulting mortality has remained largely unchanged for over 20 years in STSS $(1,4-10)$. The type and extent of tissue injury, systemic toxicity, and multiorgan system failure appear to be mediated by Spes via the induction of biologically potent endogenous cytokines (1-10). Indeed, the constellation of renal failure, shock, hypocalcemia, and thrombocytopenia is similar to that seen in staphylococcal 


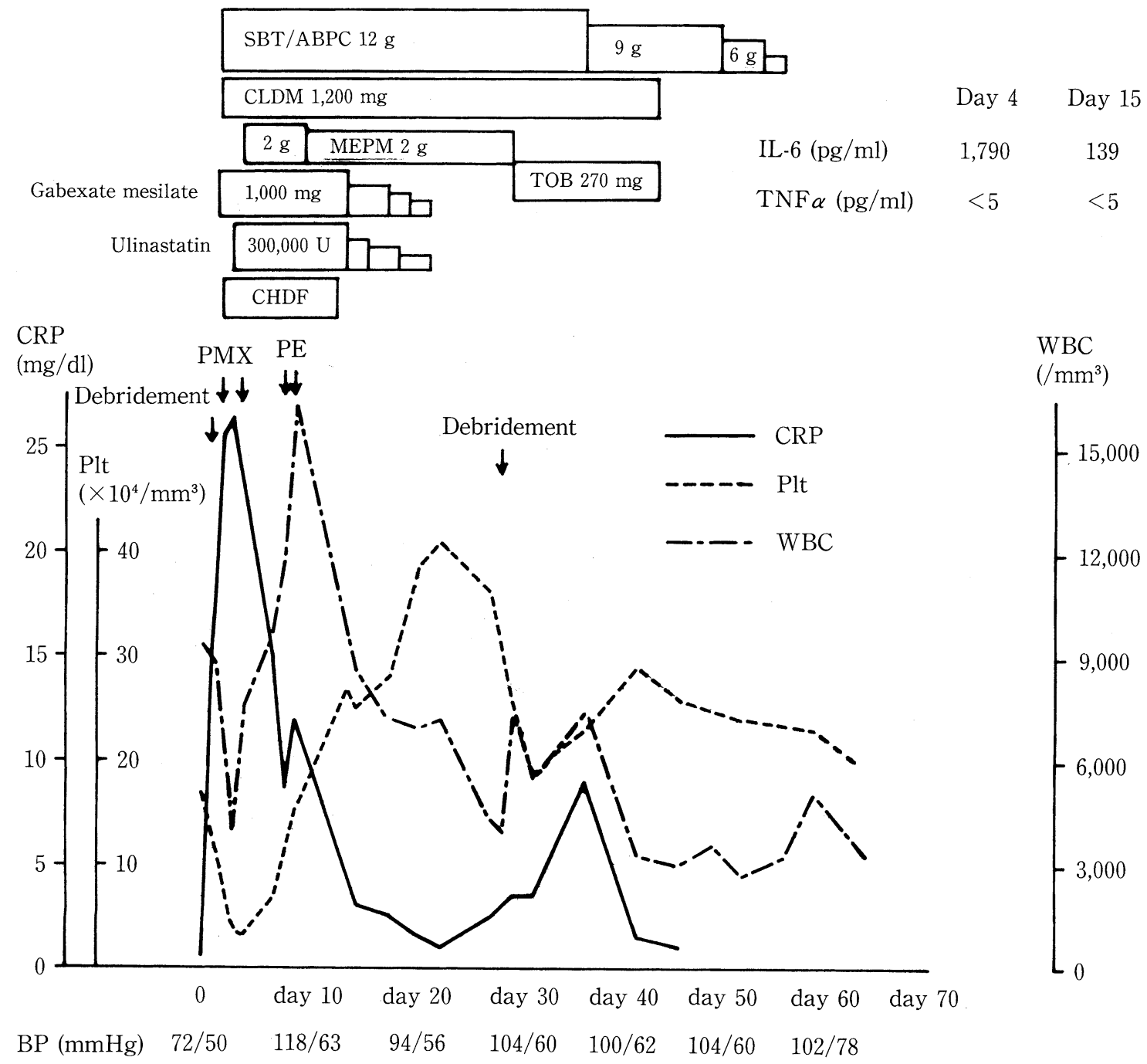

Figure 4. Clinical course of case 2. Intensive therapies caused a significant attenuation of the inflammatory signs and improvement of thrombocytopenia. IL-6 levels decreased and blood pressure improved with increments of urinary output successfully with CHDF coupled with DHP, PMX and PE. DHP, direct hemoperfusion; PMX: polymyxin Bimmobilized fiber, CHDF: continuous hemodiafiltration, PE: plasma exchange, Plt: platelet, BP: blood pressure.

toxic shock syndrome, which is clearly a toxin-mediated illness. Spes could mediate this clinical derangement, shared with toxic shock syndrome toxin-1, which includes the following: pyrogenicity, enhancement of susceptibility to endotoxin shock, enhancement of delayed hypersensitivity to induced skin rashes, cytotoxicity (including cardiac damage), mitogenicity (nonspecific) for $\mathrm{T}$ lymphocytes, immunosuppression (of B-lymphocyte function), alteration of host antibody response, and mitogenic activity in humans and in lymphocytes from rabbits (11). These facts emphasize the importance of the development of multitargeted therapeutic strategies which would theoretically attempt to neutralize the toxins or the cytokines released as a consequence of the streptococcal toxins. Therefore, we searched for innovative treatments specifically targeted to the cytokines of critically ill patients with STSS. Recent clinical trials using anticytokine therapy have failed to show amelioration of septic shock $(21,22)$. Therefore, extracorporeal therapies to reduce circulating levels of the mediators of sepsis were introduced.

The risk of death in patients with STSS increases with the need for dialytic support, but cardiovascular instability is the most common complication of dialysis. Prompt surgical intervention cannot be performed due to cardiovascular instability in patients with STSS. PMX is a biomaterial for selective absorption of endotoxin $(23,24)$. Multicenter uncontrolled clinical trials in Japan have shown that treatment with DHP with PMX ameliorates hyperdynamic shock (23) and decreases its effect on cytokine generation by 

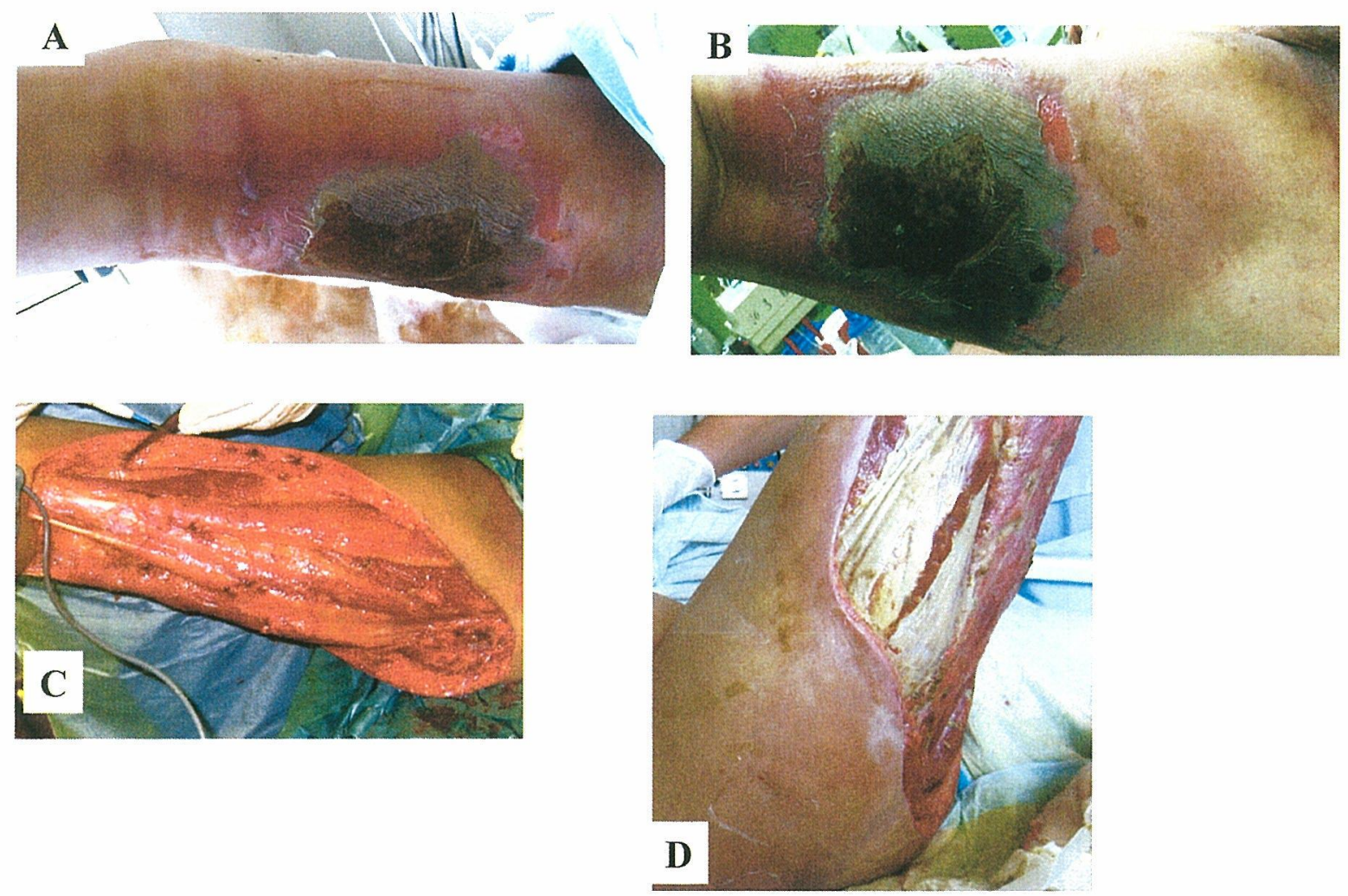

Figure 5. Photographs of case 3 show (A, B) erythematous and necrotic thigh with vesicles and bullae, (C) extensive debridement, and (D) development of the erythematous macular rash.

mononuclear cells (25), although a close relationship between the improvement in systemic hemodynamics and removal of endotoxins by DHP with PMX could not be shown. Indeed, DHP with PMX improved the hemodynamics in all 3 patients with STSS who had developed shock at presentation regardless of the level of blood endotoxins. The exact mechanism through which partial elimination of cytokines from blood stream adjusts hemodynamics could not be identified. One possible explanation may come from blocking of the synergistic interaction between Spes and endotoxins as a result of decreasing normal or physiological levels of endotoxins. Another possible explanation may be adsorption of anandamide (ANA), an endogenous cannabinoid. ANA can be generated by activated macrophages which are the pivotal cells in the signaling mechanisms, and by the resulting biological responses during septic shock; ANA is thought to be a paracrine contributor to hypotension. The adsorption of ANA by PMX (26) may abolish the diverse effects of ANA such as hypotension, immunosuppression and cytotoxicity, and may extend a new therapeutic strategy for STSS.

Several methods of dialysis for the removal of inflammatory mediators are available for renal replacement therapy (RRT) (27). IHDF increases the risk of hemodynamic instability. Indeed, cardiovascular instability followed IHDF in case 1 . On the other hand, the slow nature of CHDF allows for a slow rate of ultrafiltration with a lower impact on blood pressure. CHDF may be indicated for hemodynamically unstable patients with STSS. Accumulating evidence (28) suggests that immune-enhancing enteral preparations in critically ill patients such as STSS decrease the duration of hospital stays, the number of infections and perhaps mortality because of the severe catabolic status. Nutritional management in STSS is influenced by the modality of renal support. There are some difficulties associated with increased azotemia and the fluid overload induced by administration of protein or nutrients by means of conventional dialytic techniques. In contrast, continuous fluid removal with CHDF allows infusion of large amounts of fluids and ensures adequate caloric intake.

Due to the limited capacity of filtration with CHDF, it is very unlikely to obtain significant variations in the plasma circulating levels of inflammatory cytokines. The underlying rationale is that $\mathrm{PE}$ facilitates the removal of higher amounts of harmful bacterial products and endogenous inflammatory mediators (29). An alternative explanation is that PE simply makes room for the liberal administration of large volumes of blood products which themselves have significant immunomodulatory effects. Drenger et al (30) described the use of PE in septic patients caused by $\beta$-hemolytic streptococcus group A. They measured the plasma concentrations of TNF $\alpha$ and IL-1. The levels of both mediators were 

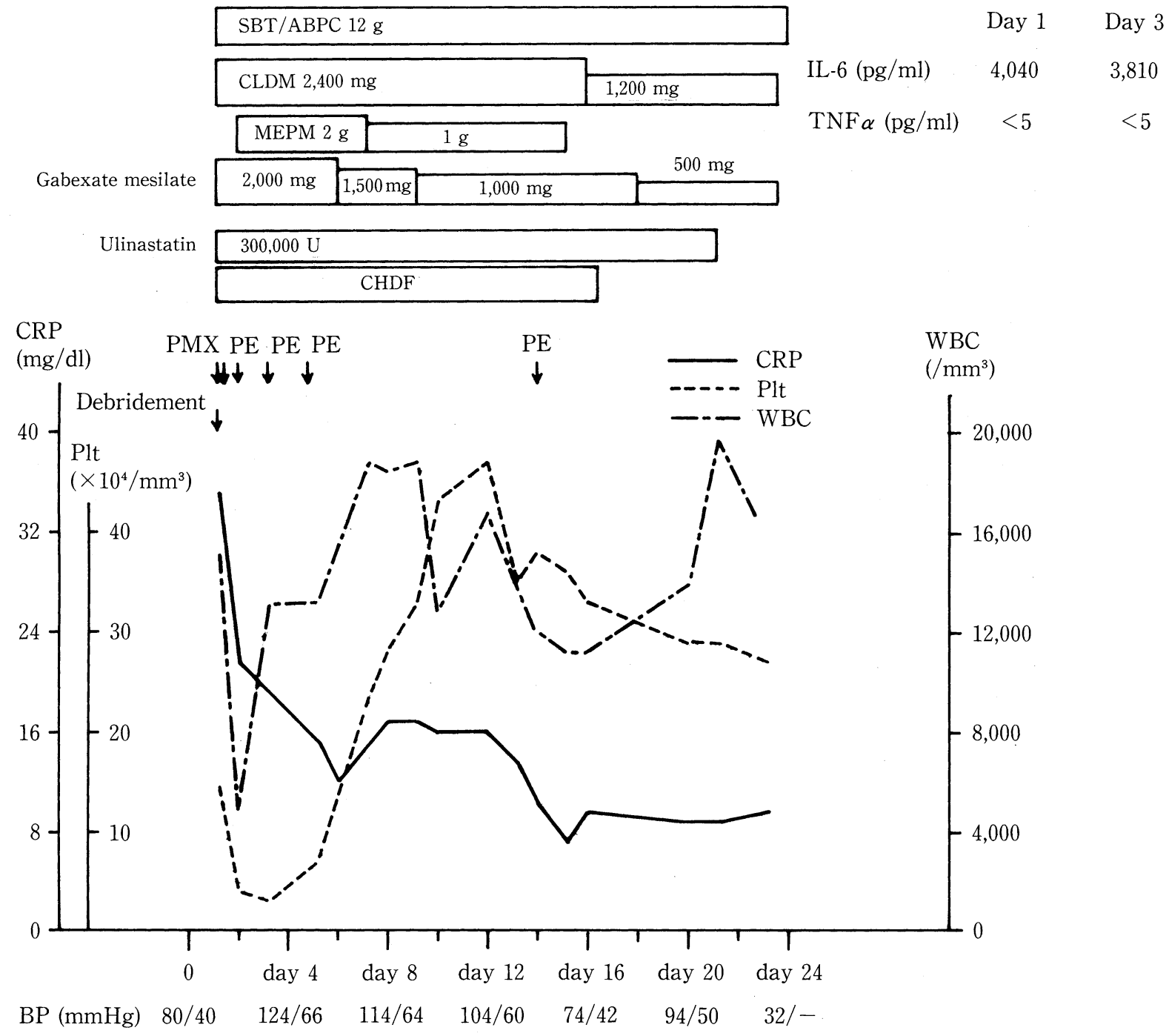

Figure 6. Clinical course of case 3. Inflammatory signs persisted and IL-6 levels remained elevated despite maximal support therapies. Blood pressure improved with increment of urinary output temporary with CHDF coupled with DHP, PMX and PE, but afterwards urinary output decreased along with continuous protein loss from wounds. DHP: direct hemoperfusion, PMX: polymyxin B-immobilized fiber, CHDF: continuous hemodiafiltration, PE: plasma exchange, Plt: platelet, BP: blood pressure.

significantly elevated at presentation and fell rapidly after PE. However, large amounts of plasma substitute and the evident cost implications may, in fact, limit the application in the treatment of STSS.

$\mathrm{TNF} \alpha$, a pleiotropic cytokine, mediates a broad spectrum of host responses to Spes. It is released from circulating and resident cells following stimulation by Spes. In case 1, the level of TNF $\alpha$ was elevated at presentation and remained elevated after DHP with PMX and IHDF which might be correlated with the severity and mortality of STSS. These findings suggest that removal of any toxigenic streptococcal foci is of paramount importance to suppress the synthesis of inflammatory mediators. TNF $\alpha$ stimulates a cascade of vasoactive and inflammatory mediators that participate in
STSS such as IL-1 $\beta$ and IL-6. In cases 2 and 3, the levels of IL-6 were remarkably elevated, while $\mathrm{TNF} \alpha$ was not detected. The reason for the discrepancy among cytokines may be explained by the different inflammatory time course or severity. The successful removal of inflammatory mediators by CHDF coupled with PE was correlated with a good outcome in case 2, while the levels of IL-6 remained elevated regardless of CHDF coupled with PE because case 3 remained febrile with superinfections. However, CHDF coupled with PE might lessen the aggressive clinical course and prolong survival.

The pathophysiology of STSS offers a highly complicated scenario. In STSS, Spes induce a complex and dynamic cellular response, giving rise to several mediators known to be 


\section{KAWAGUCHI et al}

relevant in the pathogenesis of septic shock such as specific mediators, substances responsible for up- or down-regulation of cytokine receptors and cytokine antagonists, inactivators of translational or transductional pathways, and precursor molecules. Prompt modulation of the inflammatory cascade have led to improved outcomes and to improve hemodynamics in STSS. It seems of great importance to explore all possible treatment techniques that may have a direct impact on circulating mediators of STSS and may interfere also with the imbalance between proinflammatory and antiinflammatory substances in critically ill patients with STSS. Once an optimal adsorptive substrate has been identified in STSS, the application of CHDF coupled with hemoperfusion and PE appears to open the door to effective therapeutic options. The search for innovative treatments specifically targeted to the cytokines of critically ill patients with STSS seems therefore more important than the attempt to adjust concepts and technologies that are normally applied to patients with endotoxic shock.

\section{References}

1) Stevens DL, Tanner MH, Winship J, et al. Severe group A streptococcal infections associated with a toxic shock-like syndrome and scarlet fever toxin A. N Engl J Med 321: 1-7, 1989.

2) The Working Group on Severe Streptococcal Infections. Defining the group A streptococcal toxic shock syndrome. Rationale and consensus definition. JAMA 269: 390-391, 1993.

3) Chelsom J, Halstensen A, Haga T, Hoiby EA. Necrotizing fasciitis due to group A streptococci in western Norway: incidence and clinical features. Lancet 344: 1111-1115, 1994.

4) Stevens DL. Streptococcal toxic-shock syndrome: spectrum of disease, pathogenesis, and new concepts in treatment. Emerg Infect Dis 1: 6978, 1995.

5) Kaneita Y, Tanaka C, Itobayashi E, et al. Streptococcal toxic shock syndrome: report of two cases. Intern Med 34: 643-645, 1995.

6) Wolf JE, Rabinowitz LG. Streptococcal toxic shock-like syndrome. Arch Dermatol 131: 73-77, 1995.

7) Stevens DL. Invasive group A streptococcal disease. Infect Agents Dis 5: 157-166, 1996.

8) Ayoub EM, Ahmed S. Update on complications of group A streptococcal infections. Curr Probl Pediatr 27: 90-101, 1997.

9) Stevens DL. Streptococcal toxic shock syndrome associated with necrotizing fasciitis. Ann Rev Med 51: 271-288, 2000.

10) Stevens DL. Invasive streptococcal infections. J Infect Chemother 7: 69-80, 2001.

11) Fast DJ, Schlievert PM, Nelson RD. Toxic shock syndrome-associated staphylococcal and streptococcal pyrogenic toxins are potent inducers of tumor necrosis factor production. Infect Immun 57: 291-294, 1989.

12) Braun MA, Gerlach D, Hartwig UF, et al. Stimulation of human T cells by streptococcal "superantigen" erythrogenic toxins (scarlet fever toxins). J Immunol 150: 2457-2466, 1993.

13) Hackett $S$, Stevens DL. Superantigens associated with staphylococcal and streptococcal toxic shock syndrome are potent inducers of tumor necrosis factor- $\beta$ synthesis. J Infect Dis 168: 232-235, 1993.

14) Bannan J, Visvanathan K, Zabriskie JB. Structure and function of streptococcal and staphylococcal superantigens in septic shock. Infect Dis Clin North Am 13: 387-396, 1999.

15) Bone RC. Gram-positive organisms and sepsis. Arch Intern Med 154: 26-34, 1994

16) Schor N. Acute renal failure and the sepsis syndrome. Kidney Int 61: 764-776, 2002.

17) Gemmell CG, Peterson PK, Schmeling D, et al. Potentiation of opsonization and phogocytosis of Streptococcus pyogenes following growth in the presence of clindamycin. J Clin Invest 67: 1249-1256, 1981.

18) Lamothe F, D'Amico P, Ghosn P, Tremblay C, Braidy J, Patenaude JV. Clinical usefulness of intravenous human immunoglobulins in invasive group A streptococcal infections: case report and review. Clin Infect Dis 21: 1469-1470, 1995.

19) Perez CM, Kubak BM, Cryer HG, Salehmugodam S, Vespa P, Farmer D. Adjunctive treatment of streptococcal toxic shock syndrome using intravenous immunoglobulin: case report and review. Am J Med 102: 111-113, 1997.

20) Korzets A, Ori Y, Zevin D, et al. Group A streptococcal bacteraemia and necrotizing fasciitis in a renal transplant patient: a case for intravenous immunoglobulin therapy. Nephrol Dial Transplant 17: 150-152, 2002.

21) Zeni F, Freeman B, Natanson C. Anti-inflammatory therapies to treat sepsis and septic shock: A reassessment. Crit Care Med 25: 10951100, 1997

22) Cohen J, Carlet J, INTERSEPT. An international, multicenter, placebocontrolled trial of monoclonal antibody to human tumor necrosis factor $\alpha$ in patients with sepsis. International Sepsis Trial Study Group. Crit Care Med 24: 1431-1440, 1996.

23) Shoji H, Tani T, Hanasawa K, Kodama M. Extracorporeal endotoxin removal by polymyxin $\mathrm{B}$ immobilized fiber cartridge: designing and antiendotoxin efficacy in the clinical application. [editorial] Ther Apher 2: 3-12, 1998.

24) Jaber BL, Pereira BJ. Extracorporeal adosorbent-based strategies in sepsis. Am J Kidney Dis 30: S44-S56, 1997.

25) Ebihara I, Nakamura T, Shimada N, Shoji H, Koide H. Effect of hemoperfusion with polymyxin B-immobilized fiber on plasma endothelin-1 and endothelin-1 mRNA in monocytes from patients with sepsis. Am J Kidney Dis 32: 953-961, 1998.

26) Wang $Y$, Liu $Y$, Sarker KP, et al. Polymyxin B binds to anandamide and inhibits its cytotoxic effect. FEBS Lett 470: 151-155, 2000.

27) Ronco C, Brendolan A, Dan M, et al. Adsorption in sepsis. Kidney Int Suppl 58: S148-S155, 2000.

28) Bellomo R. How to feed patients with renal dysfunction. Blood Purif 20: 296-303, 2002.

29) Reeves JH. A review of plasma exchange in sepsis. Blood Purif 20: 282-288, 2002.

30) Drenger B, Israeli A, Or R, Leitersdorf E. Plasmapheresis for streptococcal sepsis? Lancet 2: 943, 1985. 